\title{
A Test of a Personality-Based View of Intrinsic Motivation
}

\author{
Shinichiro WATANABE \\ Yuichiro KANAZAWA \\ (University of Tsukuba)
}

\begin{abstract}
The majority of research on intrinsic motivation has examined the impact of environmental factors that aroused people's needs for competence and self-determination and their influence on behavior. Relatively less attention, however, has been paid to the identification of psychological individual differences in intrinsic motivation. The present study tested a model in which a personality-based view of intrinsic motivation is prominent. Specifically, we investigated whether two of the Big-5 personality dimensions, conscientiousness and openness to experience, would affect intrinsic motivation. The results indicated that those two personality traits could be significant predictors of intrinsic motivation with the effects of taskrelated motivators (e.g., ability utilization, achievement, task variety, etc.) controlled for. The meaning of the findings and directions for future research are discussed.
\end{abstract}

Key words: intrinsic motivation; conscientiousness; openness to experience

Over the years, intrinsic motivation has been the subject of much psychological research. A fundamental reason for this topic having attracted researchers' attention lies in the generally-believed assumption that intrinsically motivated individuals consistently display higher levels of creativity, spontaneity, and concentration at a task. Most research to date has examined the impact of "external" conditions as antecedents of intrinsic motivation and has yielded evidence that feelings of challenge, competence, meaningfulness, and selfdetermination tend to be caused by interesting and challenging tasks (e.g., Lawler, 1994; Thierry, 1990; Deci \& Ryan, 1985a; Hackman \& Oldham, 1980) and by work situations placing an emphasis on autonomy and setting challenging standards for excellence (Cordova \& Lepper, 1996). The past research has made an important contribution to the literature in that it consistently

\footnotetext{
* A previous version of this study was presented at the Hot Topic Session of the 2001 Annual Conference of the Association for Psychological Science, Toronto, Canada. The research project was supported in part by the Grant-in-Aid for Scientific Research (B) 19330081 from the Japan Society for the Promotion of Science. We thank anonymous reviewers for their helpful comments on a previous version of this article. Correspondence and request for reprints should be addressed to Shinichiro Watanabe, Graduate School of Systems and Information Engineering, University of Tsukuba, 1-1-1 Tennodai, Tsukuba City, Ibaraki 305-8573 JAPAN (E-mail:watanabe@sk.tsukuba.ac.jp).
}

showed that if designed to allow a person to feel competent and self-determining in engaging in behaviors, the external conditions can be significant sources of intrinsic motivation.

A question which has not received considerable attention is whether "internal" personality traits can also promote intrinsic motivation. A major reason for the less significant efforts to solve this problem can be traced to the obvious fact that such situational conditions as reward systems and job designs are the areas in which organizations have the most leverage to influence employee motivation. Fortunately, however, past research, albeit sparse, exists that has attempted to emphasize psychological individual difference factors as determinants of motivation. For example, linking individual difference variables to intrinsic motivational orientation, Amabile, Hill, Hennessey and Tighe (1994) revealed that scores on such scales as Need for Cognition, Academic Comfort, and Investigative Vocational Interest were positively correlated with intrinsic motivation. In plain words, those individuals who tend to engage in and enjoy effortful cognitive endeavors (Need for Cognition), those who tend to persist in an educational environment (Academic Comfort), and those who like to pursue science-oriented vocational career (Investigative), tend to have a stronger intrinsic motivational orientation than their counterparts.

More recently, Komarraju, Karau, \& Schmeck (2009) investigated the effects of Big-5 personality traits on 
college students' motivational states and academic performance. As a result, they found that conscientiousness and openness were positively related to intrinsic motivation; conscientiousness and extraversion explained variance in extrinsic motivation; additionally, four personality factors (conscientiousness, openness, agreeableness and emotional stability) could be significant predictors of academic performance.

We believe that the studies by Amabile, et al's (1994) and by Komarraju, et al's (2009) have added an orthogonal element to the motivation literature in that they consistently revealed that "internal" characteristics of individuality could be significant sources of motivation. This line of research contrasts sharply with the extant research stream that has paid much (often exaggerated) emphasis on situational conditions as antecedents of intrinsic motivation. It should be noted, however, that despite the difference in focus, there is a point in common between the two camps. It is the lack of simultaneous attention to both person and situation factors in determining intrinsic motivation. Each of the camps seems to have led separate lives, with few opportunities to place equal emphasis on "internal" and "external" determinants of intrinsic motivation.

The primary purpose of this study is to propose a heuristic model in which intrinsic motivation is traced not only to person factors but also to situation factors. More specifically, collecting data from Japanese systems engineers working for a large Japanese information systems company, the model examines whether two of the Big-5 personality traits (conscientiousness and openness to experience) are significantly associated with intrinsic motivation with the effects of job intrinsic factors controlled for. If the person and job factors are significantly associated with the criterion, this will serve as evidence that intrinsic motivation derives not only from tasks a person performs but also from within the person. The examination of this problem will be a unique addition to the motivation literature.

\section{Proposed Model}

The primary purpose of this study is to propose a heuristic model of a personality-based view of intrinsic motivation. The subjects of the study are systems engineers working in a large Japanese information systems company. It has been increasing recognized that systems engineers' core work roles are not only to develop and sell new products and services on the market. To achieve sales success, they must also move away from "just developing and selling" toward "serving" as consultants and business partners for their customers. This means that they must continuously acquire not only up-to-the-minute knowledge about their products and services but also must be continuously aware of the needs of their customers. That is to say, they must "continuously learn."

A question arises as to how the organization can effectively motivate its employees to continuously learn. One solution is the use of extrinsic rewards. The consistency with which a behavior is rewarded will determine how effective the rewards will be. To provide extrinsic rewards every time the employees emit the continuous learning behavior would increase the correct behavior rapidly, but it is a costly and, in fact, almost impossible practice in the organization. For this reason it is not recommended for use by the organization to reward its employees continuously for emitting desired behavior. Past studies on operant conditioning suggest that when administering extrinsic rewards for motivating employees, the organization should adopt one or more of the following partial reinforcement schedules: fixed ratio, variable ratio, fixed interval, and variable interval schedules. It is widely known that behaviors acquired on these partial reinforcement schedules are slower to be established, but they are remarkably more persistent when no extrinsic rewards are provided.

Another solution to motivate people to continuously learn at work is to examine intrinsic rewards of a task itself as a source of motivation (see Herzberg, Mausner, \& Snyderman, 1959; Hackman \& Oldham, 1975, 1976, 1980). Herzberg's Two Factor Theory and Hackman \& Oldham's Job Characteristic Theory suggest that the organization can enrich jobs to allow its employees to assume more responsibility and accountability for planning, organizing, controlling, and evaluating their own work. The central thesis of the job enrichment approaches is the idea that the characteristics of jobs can be established to enhance workers' intrinsic work motivation and job satisfaction.

The two solutions discussed above tend to originate in the situationistic view of people that human motiva- 
tion is largely determined by situational conditions. In contrast to the situationistic view of motivation, there exists a view that human motivation comes from something "within" or from the "inner" part of the person. The personologists, espousers of this view, would insist that human motivations are largely determined by the person's internal characteristics of individuality that are relatively constant over time and consistent across situations. It is important to note again that the majority of research on intrinsic motivation has looked at situational conditions as its determinants, with paying little attention to this personologistic view of motivation.

As stated earlier, the present study is designed to test a model in which intrinsic motivation is traced to two primary determinants: conscientiousness and openness to experience on the one hand, and job content factors on the other. Figure 1 depicts the model.

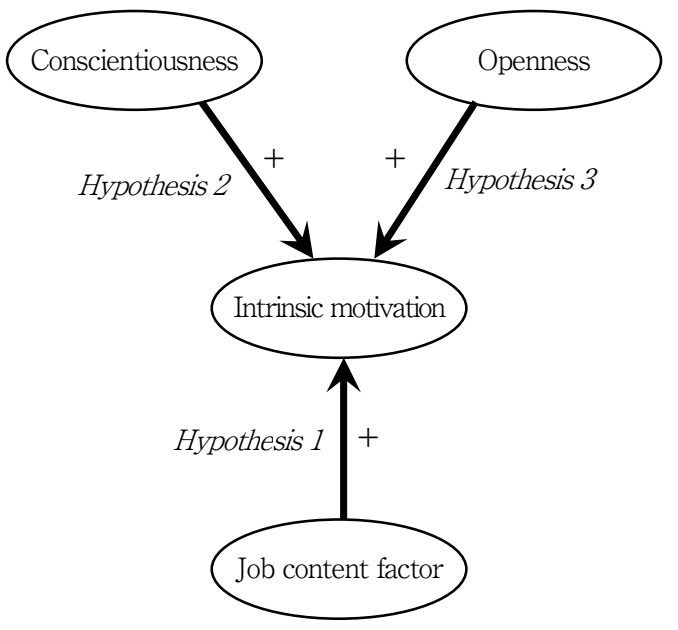

Figure 1. Proposed model of intrinsic motivation

Conscientiousness and openness to experience are two of the Big-5 personality factors originally found by Fiske (1949), ascertained since Tupes and Cristal (1961) as robust and recurrently found (see, e.g., Norman, 1963; Borgatta, 1964; Goldberg, 1981; Conley, 1985; McCrae \& Costa, 1985; Field \& Millsap, 1989; Botwin \& Buss, 1989; Tupes \& Christal, 1992). The conscientiousness factor refers to personality characteristics which primarily describes task behavior and socially prescribed impulse control (John, 1990). The personality traits frequently associated with this factor are conscietious, careful, reliable, hardworking, organized, scrupulous, self-disciplined, and so on (McCrae \& Costa, 1985). The trait descrip- tors frequently associated with the openness to experience factor, on the other hand, are original, imaginative, creative, broad-minded, curious, adventurous, and so forth (McCrae \& Costa, 1985). This factor describes the depth, complexity, and quality of a person's mental and experiential life (John, 1990).

Job content factors refers to employees' perceptions of their day-to-day task activities in terms of the extent to which the activities can be characterized by such motivators as ability utilization, achievement, activity, creativity, independence, responsibility, and task variety. This factor was included in the model as an exogenous variable affecting the level of intrinsic motivation. As stated earlier, past research shows that a work situation can be made more or less fit to the occurrence of intrinsic motivation. The present study will test the effects of psychological individual difference factors (conscientiousness and openness to experience factors of personality) on intrinsic motivation after having removed from the criterion variance due to the situational conditions (job content factor).

As for intrinsic motivation, we can find at least three different conceptualizations in the literature. First, it refers to a drive (Woodworth, 1918) that concerns the reservoir of energy that impels an organism to behave in certain ways. Woodworth is the first psychologist to outline a theory that directly addressed the issue of intrinsic motivation. He proposed that when it is initiated by its own drive, rather than by an extrinsic motive, an activity can run freely and effectively. According to this conceptualization, intrinsic motivation occurs when an activity is initiated by its drives like curiosity and self-preservation (Thierry, 1990).

Second, intrinsic motivation refers to all activities whose experience leads a person to feel a sense of competence, which has in itself a reinforcing value (White, 1959). According to this view offered by White, humans, instead of seeking to reduce tension by satisfying physiological needs, cherish the experience of raised tension and mild excitement. He argued that humans have an innate tendency to strive to exercise and extend their capabilities and that the brain is programmed to seek stimulation, and this biological seeking culminates in the desire to be competent or have feelings of competence. This suggests that people often engage in activities that are motivating in their 
own right.

The third and the most influential theorizing of intrinsic motivation comes from several sources (e.g., Deci, 1975; Deci and Porac, 1978; Deci \& Ryan, 1985a). To summarize their views, intrinsic motivation is a function of the extent to which circumstances allow a person to experience feelings of challenge, competence, and self-determination. If a task is optimally challenging, it should generally stimulate intrinsic motivation because it provides the person with the greatest opportunity to stretch his or her capacities. If external events enhance feelings of competence, as when someone is told he or she has done a task very well, intrinsic motivation is likely to increase. Important to note is Deci and Ryan's (1985a) position that feelings of selfdetermination are a necessary condition for intrinsic motivation to flourish. Thus, even if an activity is challenging and a person perceives himself or herself to be highly competent, the person will not display high levels of intrinsic motivation unless the engagement in the activity is experienced as self-determined.

Based on these conceptualizations, we define intrinsically motivated behaviors as the ones that are caused from within the person and from within the task itself and aimed at satisfying his or her innate, organismic needs for competence and self-determination. This view can be placed within a humanistic motivational tradition that emphasizes the person's being an active agent, oriented toward growth and toward choosing how to behave on the basis of evaluating both inner psychological needs and opportunities present in the environment (Mook, 1987).

\section{Person and situation as determinants of intrinsic motivation}

It should be noted that we are neither personologists nor situationists. We believe that a person's motivation is determined not only by situational conditions but also by the person's characteristics. As reviewed earlier, the past research suggests that individuals will be intrinsically motivated when they perform jobs that are high on variety, autonomy, task identity, ability utilization opportunities, and so on. Based on the theory and research reviewed above, we first propose to test the following hypothesis about the relationship between job content factor and intrinsic motivation:

Hypothesis 1. Job content factor will affect intrinsic

\section{motivation positively.}

This hypothesis predicts that the major findings from the past research would also apply to the Japanese systems engineers who participated in the present study.

The second hypothesis concerns the relationship the conscientiousness factor of personality holds with intrinsic motivation. As mentioned before, traits frequently associated with this personality factor include being careful, thorough, responsible, organized, scrupulous, hardworking, achievement-oriented, and persevering. It seems reasonable to assume that conscientious systems engineers deserve, and tend to receive, more positive competence feedback from their supervisors and customers than systems engineers who are low on this personality dimension. According to the cognitiveevaluation theory (Deci \& Ryan, 1980, 1985a), the positive competnece feedback enhances intrinsic motivation relative to negative or neutral feedback. Thus, we can assume that the effect of conscientiousness to intrinsic motivation is transmitted through positive competence feedback (conscientiousness $\rightarrow$ positive competence feedback $\rightarrow$ intrinsic motivation).

Because achievement and self-determination are the major components of conscientiousness (Barick \& Mount, 1991), it is reasonable to assume that this personality factor can also have a direct effect on intrinsic motivation (conscientiousness $\rightarrow$ intrinsic motivation). Also, the participants in the present study, systems engineers, are required to skillfully manage their products and services that are continuously evolving and require customization. This suggests that their work roles seem to have relatively high intrinsic motivational potential; the contents of their jobs are likely to be challenging and require creativity, skill variety, and achievement-oriented work behaviors. It might be argued, therefore, that conscientious work behaviors will increase the opportunities for the subjects to do things that make use of their abilities, and to experience feelings of competence and self-determination, on the job. Based on this line of thinking, we hypothesize:

\section{Hypothesis 2. Conscientiousness will affect intrinsic motivation positively.}

As stated earlier, the indirect path from conscientiousness to positive competence feedback to intrinsic motivation is also conceivable. In the present study, however, only the direct path will be tested. 
As Figure 1 indicates, openness to experience is also hypothesized to be positively related to intrinsic motivation. Thus, we have:

Hypothesis 3. Openness to experience will affect intrinsic motivation positively.

As stated previously, such trait descriptors as original, imaginative, creative, curious, adventurous, and prefer variety are frequently associated with this personality factor. People who are high on openness tend to accept and respect new experiences and desire to explore and understand things that are unfamiliar to them. Based on this line of thinking, it is reasonable to assume that systems engineers who are high on this personality factor tend to be able to find more meaningfulness and experience more feelings of competence and satisfaction in their constantly changing job requirements than those who are low on this factor. We believe that such personality characteristics lead people to assume a mastery-oriented pattern of thoughts, feelings, and behaviors, whereby challenge is pursued vigorously and in the intrinsically motivated manner.

In summary, the proposed model pays equal attention to both person and situation factors. Specifically, the model predicts intrinsic motivation from the characteristics of work roles a person performs (i.e., a situation factor) and from two of the Big-5 personality factors, conscientiousness and openness to experience (i.e., person factors). If the person factors turn out to be significant predictors with the effects of the situational conditions adjusted for, then a personality-based view of intrinsic motivation will be supported.

\section{Method}

\section{Data}

Data were collected at a large information systems company in Japan. The participants consisted of 217 systems engineers who design, manufacture and market information systems, power and industrial systems as well as business systems. The contents of the products and services they produce are continuously evolving and require customization. The production and the customization processes are technologically complex and require that the engineers not only perform their work roles in a dependable manner but also engage in creative, spontaneous, and innovative work behavior.

All surveys designed for the study were distributed to the subjects through the personnel manager of the company. To assure the respondents that their responses would be kept strictly confidential, we requested the respondents to mail the surveys directly back to us. Respondents received return envelopes addressed to us.

Of the 217 surveys distributed, 166 were completed and returned to us. The response rate was 76.5 per cent. Of the 166 respondents, approximately 91 per cent were male; and 93 per cent had bachelor's degrees. Of the 166 respondents, 143 were male and college-educated. And we selected for analysis 139 of them who provided usable data. They ranged in age from 26 to $52(\mathrm{M}=33.04 ; \mathrm{SD}=4.41)$. On average, the participants had been in the current organization for 10.2 years; and the standard deviation was 4.3 years. The range of tenure was from 19 months to 28.7 years.

\section{Measures}

Personality traits. To assess the levels of conscientiousness and openness to experience factors of personality, we extracted twelve measures from McCrae and Costa's (1985) eighty bipolar adjective scales on the basis of the results of their factor analytic study. Six trait descriptors (negligent-conscientious, carelesscareful, undependable-reliable, lazy-hardworking, disorganized-organized, and lax-scrupulous) were selected to represent the conscientiousness factor. The remaining six trait descriptors selected for the openness to experience factor consisted of conventional-original, down to earth-imaginative, uncreative-creative, narrow interests-broad interests, unadventurous-daring, and prefer routine-prefer variety.

Then we converted those bipolar adjective scales into 5-point Likert scales, where $1=$ strongly disagree, 3 $=$ neither disagree nor agree, and $5=$ strongly agree (see Appendix). For example, a bipolar adjective scale "negligent vs conscientious" for the conscientiousness factor was modified to "When doing something, I almost always pay attention to the details." And a scale "conventional vs original" for the openness factor was altered to "I often come up with original ideas by disregarding generally believed ideas." In order to measure the participants' stable personality traits, we 
instructed them to rate the question items according to how each was descriptive of the aspect of their personality that they believed was relatively stable over time and relatively consistent across many different situations. The coefficient alphas for the conscientiousness and openness to experience factors were .84 and .78 , respectively.

The psychological properties of the scales were assessed by using an independent sample of 46 registered nurses in a hospital. The data were collected at two points in time at an interval of 40 days. The internal reliabilities for the conscientiousness and openness to experience factors were both .81 at Time 1; and those at Time 2 were .80 and .72 , respectively. The testretest correlation for the conscientiousness factor was .77 ( $n=30 ; p<.001)$; for the openness factor, it was $.83(n=30 ; p<.001)$.

Moreover, the strengths of association were computed between the nurses' self-ratings of the personality traits recorded at time 1 and their scores on some specific behaviors rated by their head nurse at time 2 using 7-point scales ranging from 1 (extremely low) to 4 (average) to 7 (extemely high). Consequently, we found that the conscientiousness factor was significantly associated with such behaviors as abidance by care manuals ( $r=.34 ; p<.05 ; n=43)$ and abidance by accident prevention manuals $(r=.31 ; p<.05 ; n=43)$. The openness factor, on the other hand, was significantly related to the supervisor ratings of mastery in nursing skills $(r=31 ; p<.05 ; n=43)$ and acquisition of new knowledge and expertise $(r=.32 ; p<.05 ; n=43)$.

Job content factor. Job content factor was operationalized by a modified version of the Minnesota Importance Questionnaire (MIQ; Dawis \& Lofquist, 1984). It contains as many as twenty work-related reinforcers that seem general enough to cover a wide range of work facets. Although it was originally developed to measure the importance (need or value) of work-related outcomes, the MIQ can be utilized, via grammatical modifications of its question items, for indexing the level of experienced satisfaction (Dawis, 1992). For instance, asking "How satisfied are you with ( $x$ reinforcer)?" instead of "How important is (x-reinforcer) to you?" allows one to estimate the level of experienced satisfaction. MIQ can be modified in another way to provide perceptual measures of the extent to which employees perceive their jobs as intrinsically and/or extrinsically motivating. Presenting the subjects with reinforcer statements (e.g., I could make use of my ability) and asking them how well the statements describe their day-to-day work roles will hit the same mark. In this way, the importance measures of MIQ were transformed into the perceptual measures of intrinsic motivational potential inherent in task activities.

Seven items were selected from the MIQ that would represent the following work facets: (a) ability utilization, (b) achievement, (c) activity, (d) creativity, (e) autonomy, (f) challenge, and (g) task variety. The items to measure the levels of motivational potential in the facets of ability utilization and achievement, for example, are "I can do things on the job that make use of my ability" and "The job gives me a feeling of accomplishment," respectively. Items that did not seem to fit to the occurrence of intrinsic motivation (e.g., monetary rewards, company policies and practices, advancement, human relations with coworkers, and supervision, etc.) were excluded from the MIQ. The items for the job content factor formulated in this manner were then presented to the participants. They rated each statement using a 5-point scale ranging from strongly disagree (coded as 1), to neither disagree nor agree (coded as 3), to strongly agree (coded as 5). The inter-item reliability coefficient was .87 (see Appendix).

Intrinsic motivation. As discussed previously, intrinsically oriented behaviors can be portrayed in terms of the extent to which individuals perceive that their actions are aimed at satisfying their internal needs for competence and self-determination, rather than controlled by such external (social and environmental) forces as threats, deadlines, surveillance, explicit competition, and extrinsic rewards. In the context of the present study, intrinsically oriented work behavior occurs when a systems engineer is engaged in his work roles because of their inherent qualities, such as their interest values or levels of challenge, but not because of some external influences (e.g., money, employee benefits, physical work environment, and special privileges). We also assume that if he is intrinsically motivated toward his tasks, the engineer perceives that the mastery of the task is a enjoyable process and is an end in itself.

There are several measures to assess intrinsic moti- 
vation, such as General Causality Orientation Scale (Deci \& Ryan, 1985b), Work Preference Inventory (WPI; Amabile, Hill, Hennessey, \& Tighe, 1994), and PLOC (perceived locus of control) measures (Sheldon \& Kasser, 1995, 1998). Although it was originally designed to assess general causality orientations that might result in intrinsic or extrinsic motivations, Deci and Ryan's scale can be modified so that the assessment of intrinsic and extrinsic motivational states, rather than individual differences in motivational orientations, can be made. The Work Preference Inventory, on the other hand, is designed to directly assess intrinsic and extrinsic motivations. A point in common between Deci and Ryan's and Amabile et al's scales is that every single item is formulated to index the strength of either an intrinsic motive (e.g., Curiosity is the drive force behind much of what I do) or an extrinsic motive (e.g., I believe that there is no point in doing a good job if nobody else knows about it). Although it seems appropriate in studies aimed at proving or disproving the coexistence of both motivations, the use of items like these does not allow respondents to explicitly compare which motive is stronger in their daily task activities. Thus, we believe that additional items, if included to make such comparisons possible (e.g., I perform my work roles for the fun of it, rather than for getting recognition from others), would lead to an improvement in the assessment of motives. The PLOC measures are often used to assess degrees of self-determination in pursuing goals. Since what we would like to assess in this study is the strength of intrinsic motivation directed to dayto-day task activities (not to a particular goal), the PLOC scales are not appropriate for use in the present study.

With the discussions about the existing measures in mind, we constructed an eight-item intrinsic motivation scale. Sample items included "I am willing to undertake challenging jobs even if successfully performing them will not result in a promotion" and "I seek satisfaction from doing interesting tasks, rather than from such work outcomes as promotions and raises in salary." Each of the items included five response alternatives ranging from 1 (strongly disagree) to 3 (neither disagree nor agree) to 5 (strongly agree). The coefficient alpha was .75 (see Appendix). It is important to note that several systems engineers with over 20 years of experience on the research site participated in the item writing process.

To assess the psychological properties of the scale, we used the aforementioned nurse data again. The nurses were asked to fill out the 8-item intrinsic motivation scale we designed for this study at two points in time (40-day interval). The internal reliability coefficients for the scale were .83 at Time 1 and .89 at Time 2. The test-retest reliability was $.81(p<.001 ; n=28)$. The scores recorded at Time 1 were then associated with a 7-point measure of overall job performance recorded by the head nurses at Time 2. The correlation reached $.42(n=43, p<.01)$, providing evidence for predictive validity.

\section{Analyses}

LISREL 8.8 (Jöreskog \& Sörbom, 1993) was used to test the proposed model. We simultaneously estimated the parameters for the measurement models and for the structural equation model by maximum likelihood (ML) method using the Polychoric correlation matrix of the manifest variables.

In order to test the model, we first set all covariances among the measurement errors to be zero. We then modified the model by relaxing the restriction of no correlations on the measurement errors according to the modification indices in LISREL for the following reason. That is, if the correlations among the measurement items are induced by a set of latent variables, then when all latent variables are accounted for, the measurement errors will be uncorrelated. Since we assume one latent variable for a group of measurement items, it is expected that measurement errors are likely to be correlated.

\section{Results}

Table 1 presents correlations among intrinsic motivation, openness, conscientiousness, job content factor, age, and company tenure. In addition, scale coefficient alphas, means, standard deviations, and ranges are reported for these variables. Examination of the table reveals that both personality and job content factors are strongly correlated with intrinsic motivation. The results also indicate that scores on the conscientiousness and openness factors are not correlated with each other $(r=.14$, n.S.), providing evidence that each of the 
Table 1. Descriptive information, reliabilities, and correlations among variables used in the present study

\begin{tabular}{|c|c|c|c|c|c|c|c|c|c|}
\hline & & $\alpha$ & Means & $\begin{array}{l}\text { Ranges } \\
\text { min. }\end{array}$ & & scientiol & $\begin{array}{l}\text { s } \\
\text { relation }\end{array}$ & & \\
\hline & ables & (items) & (s.d.) & $\max$. & 1 & 2 & 3 & 4 & 5 \\
\hline 1. & Intrinsic motivation & .75 & 26.38 & 13.00 & & & & & \\
\hline & & (8) & (3.61) & 38.00 & & & & & \\
\hline 2. & Openness & .78 & 20.29 & 11.00 & $.41^{* * *}$ & & & & \\
\hline & & (6) & (3.26) & 30.00 & & & & & \\
\hline 3. & Conscientiousness & .84 & 19.53 & 9.00 & $.26^{* * *}$ & .14 & & & \\
\hline & & (6) & (3.58) & 30.00 & & & & & \\
\hline 4. & Job content factor & .87 & 23.53 & 11.00 & $.46^{* * *}$ & $.22^{* * *}$ & $.37^{* * *}$ & & \\
\hline & & (7) & (3.94) & 35.00 & & & & & \\
\hline 5. & Age & & 33.04 & 26.00 & -.04 & -.02 & .10 & .03 & \\
\hline & & & $(4.41)$ & 52.00 & & & & & \\
\hline 6. & Tenure (months) & & 122.24 & 19.00 & -.04 & -.01 & .11 & .06 & $.95^{* * *}$ \\
\hline & & & $(51.24)$ & 344.00 & & & & & \\
\hline
\end{tabular}

Note: $n=139 ;{ }^{\text {**** }} p<.001$ (two-tailed)

constructs is dissimilar to each other (discriminant validity).

Age, which is suggested by past research to be positively linked to intrinsic motivation (see Kackmar \& Ferris, 1989; Rhodes, 1983), did not reach statistical significance. Past research suggests that since people move from job to job until they find one they like and then stay in that job, older workers tend to be more satisfied with, and more intrinsically motivated toward, their jobs than their younger counterparts. This age effect, however, was not found for the sample of the present study. A possible reason for this is that due to the still-lively Japanese life-time employment systems together with the distinctive skills and abilities required of systems engineers for successful performance, the participants in the study seem to have continued to stayed in the same job in the same organization for a longer period of time than those individuals who have different types of jobs. The extremely strong positive correlation found between age and company tenure $(r$ $=.95, p<.001)$ is supportive of this reasoning.

Table 2 shows the completely standardized estimates of loadings $(\lambda)$ and $t$-values for the measurement models. As shown in the table, all measurement items were significant $(p<.001)$, indicating that the four latent variables - conscientiousness, openness to experience, job content factor, and intrinsic motivationwere measured fairly well.

Having checked the results of the measurement models, we then focused on the results of the structural equation model. Figure 2 reports the completely stan-
Table 2. Results for measurement models

\begin{tabular}{|c|c|c|c|}
\hline Latent Variables & Items & $\lambda$ & $t$-values \\
\hline $\begin{array}{l}\text { Conscientiousness (C) } \\
(\boldsymbol{\alpha}=.84)\end{array}$ & $\begin{array}{l}\mathrm{C} 1 \\
\mathrm{C} 2 \\
\mathrm{C} 3 \\
\mathrm{C} 4 \\
\mathrm{C} 5 \\
\mathrm{C} 6\end{array}$ & $\begin{array}{l}.66 \\
.74 \\
.74 \\
.79 \\
.66 \\
.85\end{array}$ & $\begin{array}{r}8.37 \\
11.06 \\
10.58 \\
12.83 \\
8.82 \\
15.76\end{array}$ \\
\hline $\begin{array}{l}\text { Openness to experience }(\mathrm{O}) \\
(\boldsymbol{\alpha}=.78)\end{array}$ & $\begin{array}{l}\mathrm{O} 1 \\
\mathrm{O} 2 \\
\mathrm{O} 3 \\
\mathrm{O} 4 \\
\mathrm{O} 5 \\
\mathrm{O} 6\end{array}$ & $\begin{array}{l}.58 \\
.62 \\
.73 \\
.85 \\
.53 \\
.68\end{array}$ & $\begin{array}{r}7.12 \\
7.43 \\
11.77 \\
14.11 \\
5.22 \\
10.65\end{array}$ \\
\hline $\begin{array}{l}\text { Job content factor }(\mathrm{J}) \\
\qquad(\boldsymbol{\alpha}=.87)\end{array}$ & $\begin{array}{l}\mathrm{J} 1 \\
\mathrm{~J} 2 \\
\mathrm{~J} 3 \\
\mathrm{~J} 4 \\
\mathrm{~J} 5 \\
\mathrm{~J} 6 \\
\mathrm{~J} 7\end{array}$ & $\begin{array}{l}.82 \\
.86 \\
.73 \\
.71 \\
.66 \\
.67 \\
.76\end{array}$ & $\begin{array}{r}13.60 \\
15.12 \\
10.32 \\
11.02 \\
9.10 \\
9.31 \\
11.82\end{array}$ \\
\hline $\begin{array}{l}\text { Intrinsic motivation (I) } \\
(\alpha=.75)\end{array}$ & $\begin{array}{l}\text { I1 } \\
\text { I2 } \\
\text { I3 } \\
\text { I4 } \\
\text { I5 } \\
\text { I6 } \\
\text { I7 } \\
\text { I8 }\end{array}$ & $\begin{array}{l}.48 \\
.48 \\
.78 \\
.39 \\
.38 \\
.46 \\
.91 \\
.57\end{array}$ & $\begin{array}{r}5.09 \\
5.25 \\
9.06 \\
3.89 \\
3.88 \\
4.53 \\
14.66 \\
6.06\end{array}$ \\
\hline
\end{tabular}

$\overline{\text { Note: All measurement items were significant at the } 0.1 \% \text { level }}$ 


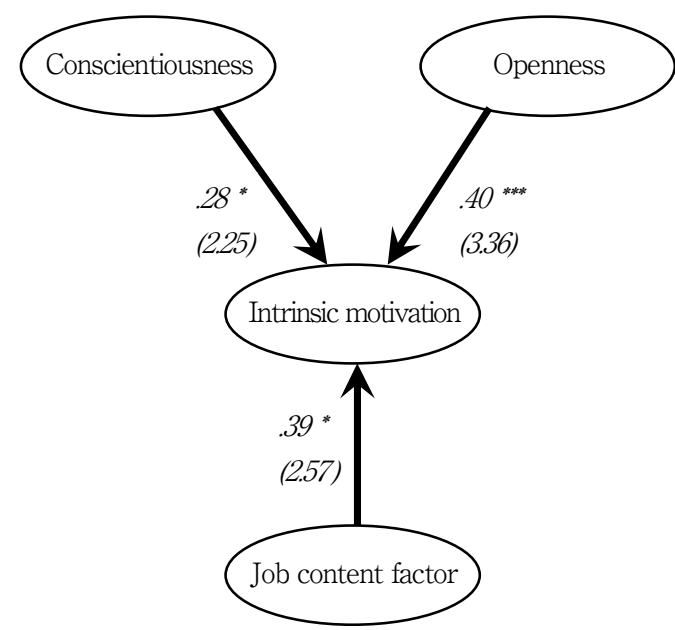

Note: $t$-values are in parentheses. ${ }^{*} p<.05 ;{ }^{* * * * *} p<.001$

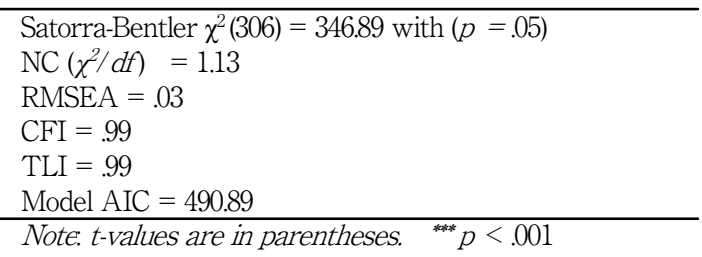

Figure 2. Results of LISREL analysis for testing Hypotheses 1 through 3

dardized estimates of the path coefficients and the overall goodness-of-fit statistics.

Hypothesis 1 concerned the effect of the job content factor on intrinsic motivation. As shown in the figure, the path coefficient was .39 and statistically significant $(t=2.57, p<.05)$, providing support for the hypothesis. Hypotheses 2 and 3 proposed positive direct effects of openness to experience and conscientiousness factors of personality on the criterion. As expected, the path from the openness factor $(\beta=.40, t=3.36, p<.001)$ and that from the conscientiousness factor $(\beta=28, t=2.25$, $p<.05)$ were positive and significant. Most of the overall goodness-of-fit statistics are supportive of the model $(\mathrm{NC}=1.13 \text {; } \mathrm{RMSEA}=.03 \text {; } \mathrm{CFI}=.99 \text {; } \mathrm{TLI}=.99)^{1}$, except for the fit index to test for difference in values in the sample covariance matrix $S$ and the reproduced implied matrix $\sum$ specified by the proposed model (Satorra-Bentler $\left.\chi^{2}(306)=346.89 ; p=.05\right)$. It should be noted, however, that the sample size for the study is relatively small $(n=139)$ and that the proposed model included as many as 27 manifest variables to evaluate its measurement models. In such a case, the $\chi^{2}$ statistic is not an appropriate index of model fit. Thus, it is

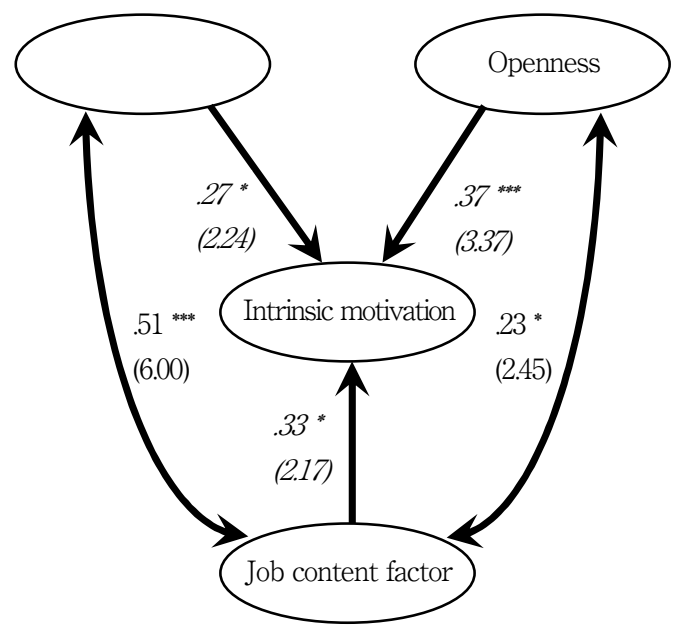

Note: $t$-values are in parentheses. ${ }^{*} p<.05 ;{ }^{* * * * *} p<.001$

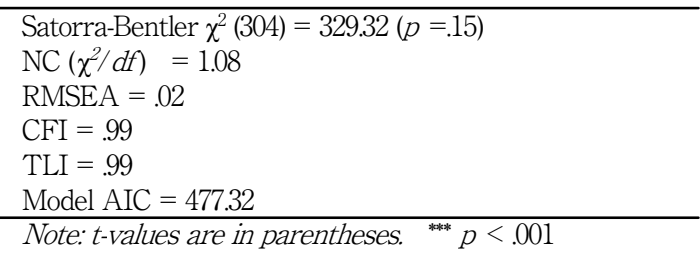

Figure 3. A test of an alternative model of intrinsic motivation

our conclusion that we have successfully located a model and a set of coefficient estimates that are consistent with the observed variances and covariances. ${ }^{1} \mathrm{An}$ alternative model was tested by relaxing the constraints of independence between openness and job content factor and between conscientiousness and job content factor. The construction of the model comes from Schneider's (1987) ASA framework, which holds that people are attracted to, or try to choose, work environments that fit their personality. This suggests that those individuals who are high on openness would be attracted to and try to select work environment that can afford opportunities of creativity and discretion at a task. Likewise, since achievement and selfdetermination are the major components of conscientiousness, those who are high on this trait would also

1 One of the most frequently reported fit indices, GFI, is known to be affected by sample size and thus can be large for poorly specified models. The current consensus, therefore, is not to use GFI as an appropriate fit index (see Bollen \& Long, 1993; Munro, 2004; among others). For this reason, GFI is not reported in this study. 
prefer tasks that afford high degrees of ability utilization and decision latitude. As Table 1 indicates, job content factor is strongly associated with openness $(r$ $=.22$ ) and conscientiousness $(r=.37)$, both significant at the .001 level.

Figure 3 reports the standardized estimates of the coefficients for the interrelations between the person and situation factors and for the causal relations among the latent factors. As expected, the positive and significant correlations were found between openness and job content factor $(r=.23 ; p<.05)$ and between conscientiousness and job content factor $(r=.51 ; p<.001)$. The coefficients $\beta$ for the alternative model were similar to those obtained for the original model. The overall goodness-of-fit statistics found for the model are Satorra-Bentler $\chi^{2}(304)=329.32(p=.15), \mathrm{NC}=1.08$, RMSEA $=.02, \mathrm{CFI}=.99, \mathrm{TLI}=.99$, and $\mathrm{AIC}=477.32$. The results suggest that the alternative model, in which the two constraints of independence were relaxed, seems to fit the data significantly better than do the original model.

In summary, the data suggested that Japanese systems engineers who enjoy the opportunities in their jobs that allow them to try out their own ideas and utilize their valued skills and abilities tend to elicit more intrinsically motivated work efforts. These results are consistent with those obtained in the existing avenues of research (both experimental and field studies) that examined the effects of enriched tasks on intrinsic motivation (Herzberg, Mausner, \& Snyderman, 1959; Hackman \& Oldham, 1975, 1976, 1980; Cordova \& Lepper, 1996; Pelleitier \& Vallerand, 1996; Elliot \& Harackiewicz, 1996). In addition, the present study demonstrated that stable personality traits that are "inside" of the person could also be significant sources of intrinsic motivation. Specifically, we found that those systems engineers who prefer creative work environments to do things that make use of their original thoughts and ideas (openness) and those who are organized and scrupulous in performing their work roles (conscientiousness) tended to experience higher levels of work intrinsic motivation than those who are low on these traits.

\section{Discussion}

Since Deci and Ryan (1985a) posited that intrinsic motivation is based in innate, organismic needs for competence and self-determination, research on intrinsic motivation has examined the impact of external events that aroused the needs and their influence on behavior. However, relatively little attention has been paid to the identification of individual differences in intrinsic motivation.

The present study proposed a model in which intrinsic motivation was traced to two primary determinants. One, a job content factor, is the extent to which employees perceive their day-to-day task activities to be providing such opportunities as ability utilization, achievement, independence, etc. A second determinant consisted of two of the Big-5 personality factors, conscientiousness and openness to experience. We hypothesized that those personality traits would promote intrinsic motivation for systems engineers working in a Japanese large information systems company. Controlling for the impact of job characteristics that are "external" to the participants, the data suggested that the levels of the engineers' intrinsic motivation were predictable from conscientiousness and openness to experience that are "internal" to them.

\section{Theoretical implications}

The results of this study challenges two major traditions in work motivation research - the situationist school and the personologist school. The situationist school posits that a person's motivation is caused primarily by situational characteristics to which a person responds and places much (often exaggerated) emphasis on job characteristics as the source of motivation. The personologist school, on the other hand, postulates that the person's motivation is a function of the enduring attributes of the person that are consistent over time and across situations and attempts at identifying psychological individual differences in motivation with relatively less attention to the detailed characteristics of the task activities the person performs.

A theme that runs through the present study is the notion that motivation is a function of both person and situation factors. We placed equal emphasis on those two factors and examined the effects of personality traits and perceived job characteristics on intrinsic motivation. Cleary, as shown in past research, situational factors played an important role in shaping or deter- 
mining people's intrinsic motivational states. In addition, we found that internal characteristics of individuality (conscientiousness and openness) could also predict the level of intrinsic motivation with the effects of the situational conditions controlled for. These findings suggest to us that in the study of motivation, both person and situation factors be considered simultaneously and with equal emphasis, without either one of the two being kept in isolation from the other.

\section{Practical implications}

Similar to researchers, practitioners need to understand that instead of just looking at employees' job characteristics alone, they should also examine the employees' internal characteristics of individuality. The traditional work design approach by Hackman and Oldham $(1975,1976,1980)$ suggests that by fitting jobs to people (i.e., providing enriched jobs to people with strong growth need strength), an organization can positively affect its employees' intrinsic motivation. We agree, and would like to make an additional statement that fitting jobs to individuals' personality traits, as well as to their need states, will be an interesting problem to address in future workplace.

Another possible way to increase the levels of people's intrinsic motivation in the organization is to hire people who are high on openness and conscientiousness. This solution will be effective, especially when the jobs the organization seeks to fill require high levels of fluid abilities to acquire and develop new knowledge and skills for successful performance. Still another way is to try to raise the levels of openness and conscientiousness of people already in the organization; however, this solution will not come easily, given the relative stability of people's personality traits.

\section{Limitations and future research directions}

The results presented in this study would serve as a nice starting point for future research, but it is important to discuss the study's limitations. One limitation is the small sample size $(n=139)$, which did not allow us to explore the interactive effects between the personality traits and the job characteristics. It will be an interesting research topic to examine whether the effects of those person and situation factors on intrinsic motivation are additive and/or interactive in nature.
The positive effects of the enriched jobs on intrinsic motivation may be more pronounced for those employees who are high on conscientiousness and openness to experience.

Another limitation concerns the model specification. Past research shows that various forms of job extrinsic facets (e.g., pay, promotion, supervision, job security, etc.) have thwarting effects on people's natural tendency to persist at challenging and interesting activities. Thus, the model should have included the job extrinsic factors as important exogenous variables.

A third limitation is that the data were collected just at one point in time, assuming that the predictorcriterion relationships were stable over time. This is a weak assumption, unless proven in studies that deal with time-structured data. Future studies should collect data at multiple points in time to examine the longterm stability of the effects of the situation and person factors on intrinsic motivation.

Finally, the generalizability of the findings becomes a concern. Since the participants in the present study consisted of systems engineers in a Japanese company, this research is mute as to whether the results can be generalized across different occupations, different industries, and different cultures. Future research is needed to investigate this point.

\section{Conclusion}

Despite the limitations discussed, we believe that the results of the present study added an important contribution to the motivation literature by empirically demonstrating the positive direct links from conscientiousness and openness to experience to intrinsic motivation, as well as the link from job content factor to intrinsic motivation. Future motivational research has many interesting problems to address, such as those pointed out above. We hope that the findings of the present study and the knowledge of its limitations will serve as the foundation for developing future motivation research. 


\section{References}

Amabile, T. M., Hill, K. G., Hennessey, B. A., \& Tighe, E. M. 1994 The work preference inventory: Assessing intrinsic and extrinsic motivational orientations. Journal of Personality and Social Psychology, 66, 5, 950-967.

Barick, M. R., \& Mount, M. K. 1991 The Big Five personality dimensions and job performance: A metaanalysis. Personnel Psychology, 44, 1-26.

Bollen, K. A., \& Long, J. S. 1993 Testing structural equation models. Newbury Park, CA: Sage.

Borgatta, E. F. 1964 The structure of personality characteristics. Behavioral Science, 9, 8-17.

Botwin, M. D., \& Buss, D. M. 1989 Structure of actreport data: Is the five factor model of personality recaptured? Journal of Personality and Social PSychology, 56, 988-1001.

Conley, J. J. 1985 Longitudinal stability of personality traits: A multitrait-multimethod-multioccasion analysis. Journal of Personality and Social Psychology, 49, 1266-1282.

Cordova, D. I., \& Lepper, M. R. 1996 Intrinsic motivation and the process of learning: Beneficial effects of contextualization, personalization, and choice. Journal of Educational Psychology, 88 (4), 715-730.

Dawis, R. V., \& Lofquist, L. H. 1984 A psychological theory of work-adjustment. Minneapolis, MN: University of Minnesota Press.

Dawis, R. V. 1992 Person-environment fit and job satisfaction. In C. J. Cranny, P. C. Smith, \& E.F. Stone (Eds.), Job satisfaction: How people feel about their jobs and how it affects their performance, 67-88. New York: Lexington Books.

Deci, E. L. 1975 Intrinsic motivation. New York: Plenum Press.

Deci, E. L., \& Porac, J. 1978 Cognitive evaluation theory and the study of human motivation. In M.R. Lepper \& D. Green (Eds.), The hidden costs of reward. New York: Wiley.

Deci, E. L., \& Ryan, R. M. 1985a Intrinsic motivation and self-determination in human behavior. New York: Plenum Press.

Deci, E. L., \& Ryan, R. M. 1985b The general causality orientations scale: Self-determination in personality. Journal of Research in Personality, 19, 109-134.
Elliot, A. J., \& Harackiewicz, J. M. 1996 Approach and avoidance achievement goals and intrinsic motivation: A mediational analysis. Journal of Personality \& Social Psychology, 70 (3), 461-475.

Field, D., \& Millsap, R. E. 1989 Personality in advanced old age: Continuity or change? Unpublished manuscript. Institute of Human Development, University of California at Berkeley.

Fiske, D. W. 1949 Consistency of the factorial structures of personality ratings from different sources. Journal of Abnormal and Social Psychology, 44, 329-344.

Goldberg, L. R. 1981 Language and individual differences: The search for universals in personality lexicons. In L. Wheeler (Ed.) Review of Personality and Social Psychology, (Vol. 2), 141-165. Beverly Hills, CA: Sage.

Hackman, J. R., \& Oldham, G. R. 1975 Development of the job diagnostic survey. Journal of Applied PSychology, 60, 159-170.

Hackman, J. R. \& Oldham, G. R. 1976 Motivation through the design of work: Test of a theory. Organizational Behavior and Human Performance, 16, 250-279.

Hackman, J. R., \& Oldham, G. 1980 Work redesign. Reading, MA: Addison-Wesley.

Herzberg, F., Mausner, B., \&n Snyderman, B. B. 1959 The motivation to work. New York: Wiley.

John, O. P. 1990 The "big five" factor taxonomy: Dimensions of personality in the natural language and in questionnaires. In L.A. Pervin (Ed.) Handbook of personality: Theory and research, 66-100. New York / London: Guilford Press.

Jöreskog, K. G., \& Sörborn, D. 1993 Lisrel 8: Structural equation modeling with the SIMPLIS command language. Chicago: Scientific Software International.

Kackmar, K. M., \& Ferris, G. R. 1989 Theoretical and methodological considerations in the age-job satisfaction relationship. Journal of Applied Psychology, 74, 201-207.

Komarraju, M., Karau, S. J., \& Schmeck, R. R. 2009 Role of the big five personality traits in predicting college students' academic motivation and achievement. Learning and Individual Differences, 19, 1. 47-52.

Lawler, E. E. III 1994 Motivation in work organization. 
San Francisco: Jossey-Bass.

McCrae, R. R., \& Costa, P. T. 1985 Updating Norman's adequate taxonomy: Intelligence and personality dimensions in natural language and in questionnaires. Journal of Personality and Social Psychology, 49, 710-721.

Munro, B. H. 2004 Statistical methods for health care research (5th Edition), Lippincott Williams \& Wilkins.

Mook, D. G. 1987 Motivation: The organization of action. New York: Norton.

Norman, W. T. 1963 Toward an adequate taxonomy of personality attributes: Replicated factor structure in peer nomination personality ratings. Journal of Abnormal and Social Psychology, 66, 574-583.

Pelleitier, L. G., \& Vallerand, R. J. 1996 Supervisors' beliefs and subordinates' intrinsic motivation: A behavioral confirmation analysis. Journal of Personality \& Social Psychology. 71 (2), 331-340.

Rhodes, S. R. 1983 Age-related differences in work attitudes and behavior: A review and conceptual analysis. Psychological Bulletin, 93, 328-367.

Schneider, B. 1987 The people make the place. Personnel Psychology, 40, 437-453.

Sheldon, K. M., \& Kasser, T. 1995 Coherence and congruence: Two aspects of personality integration. Journal of Personality and Social Psychology, 68, 531-543.

Sheldon, K. M., \& Kasser, T. 1998 Pursuing personal goals: Skills enable progress but not all progress is beneficial. Personality and Social Psychology Bulletin, 24, 1319-1331.

Thierry, H. 1990 Intrinsic motivation reconsidered. In Keinbeg, U., Quast, H., Thierry, H., \& Häcker, H. (Eds.), Work motivation, 67-82, New Jersey: Lawrence Erlbaum.

Tupes, E. C., \& Christal, R. E. 1961 Recurrent personality factors based on trait ratings (Tech. Rep. No. ASDTR-61-97). Lackland Air Force Base, TX: U.S Air Force.

Tupes, E. C., \& Christal, R. E. 1992 Recurrent personality factors based on trait ratings. Journal of Personality, 60, 225-251.

White, R. W. 1959 Motivation reconsidered: The concept of competence. Psychological Review, 66, 297333.
Woodworth, R. S. 1918 Dynamic psychology. New York: Columbia University Press.

(Received March 13, 2009 Accepted August 10, 2009) 


\section{Appendix}

Conscientiousness

C1. I usually prepare thoroughly.

C2. I do things methodically.

C3. I always organize my thoughts before making a speech.

C4. When doing something, I almost always pay attention to the details.

C5. I tend to use a systematic approach to guide my thinking.

C6. I put effort into ensuring that there will be no mistakes.

Openness to experience

O1. I am interested in many different things.

O2. I often come up with creative and novel ideas by disregarding generally accepted ideas.

O3. I prefer an environment where I can be creative.

O4. I tend to prefer variety.

O5. I am very interested in things that are novel and unknown.

O6. Many people say that I am adventurous.

Job content factor

J1. My job keeps me busy all the time.

J2. I can work independently on the job.

J3. I can try out new things on the job.

J4. I can do things on the job that make use of my ability.

J5. I can make job-related decisions on my own.

J6. I can try out my original ways of performing my job.

J7. The job gives me a feeling of accomplishment.

Intrinsic motivation

I1. My work efforts are directed to the inherent qualities of my job, such as its interest value, rather than to getting recognition from others.

I2. I work mainly because I want to stretch my abilities.

I3. I seek to increase my competence through work.
I4. I am willing to undertake challenging jobs even if successfully performing them will not result in a promotion

I5. I always seek tasks that require my best efforts.

I6. I seek satisfaction from doing interesting tasks, rather than from such work outcomes as promotions and raises in salary.

I7. I prefer challenging tasks that provide me with a sense of excitement.

I8. I prefer difficult tasks that satisfy my need for growth. 